\title{
TREINAMENTO E TÉCNICAS DE VENDAS EM UMA ADMINISTRADORA DE CARTÃO DE CRÉDITO: MOTIVANDO PARA ALCANÇAR RESULTADOS
}

\author{
Eduardo Mendes da Silva ${ }^{1}$ \\ Marcelo Augusto Alves ${ }^{2}$ \\ Thiago Fernando Aguiar ${ }^{3}$ \\ Marcus Venicius dos Santos ${ }^{4}$
}

Resumo: Este trabalho apresenta a evolução de vendas de uma Administradora de Cartões de Crédito que possui produtos oferecidos no mercado por uma equipe interna de vendas, permeio do telemarketing. Tal evolução é medida a partir de uma consultoria que identifica a influência da motivação da equipe interna em seus resultados. Trata-se de um estudo bibliográfico, obtido através de revisão literária, que traz os conceitos de marketing, vendas e comportamento organizacional. Seguido de aplicação de técnicas de motivação; executando campanhas de vendas e treinamentos, onde é apresentada a prática do grande desafio de alinhar os objetivos da equipe aos da empresa. O resultado da motivação da equipe é a potencialização de $27 \%$ do aumento de vendas dos produtos da administradora, comprovado a partir da análise de dados quantitativos que fazem referência aos produtos vendidos em um mesmo período (Jan/15 a Mai/15 $x$ Jan/16 a Mai/16).

Palavras-chave: Marketing; Telemarketing; Motivação; Venda; Consultoria.

\footnotetext{
1 Universidade Paulista - Unip, Brasil. E-mail: eduardoo.msilva@gmail.com.

2 Universidade Paulista - Unip, Brasil. E-mail: marceloaug@hotmail.com.

3 Universidade Paulista - Unip, Brasil. E-mail: tfaguiar@yahoo.com.br.

4 Universidade Paulista - Unip, Brasil. E-mail: sjc.pos@unip.br.
} 